Artículo de Reflexión

A puntes del CEN ES

ISSN 0120-3053

Volumen 32 - №. 56

Julio - Diciembre de 2013

Págs. 105-138

\title{
Instituciones y tecnología como factores clave en los proyectos nacionales del desarrollo: un análisis comparativo de Brasil y México
}

\section{Institutions and technology as key components of national development projects: a comparative analysis of Brazil and Mexico}

James Martín Cypher*

Aldo Alejandro Pérez-Estcatel**

Fecha de recepción: 9 de abril de 2013

Nueva versión: 2 de mayo de 2013

Fecha de aprobación: 28 de mayo de 2013

* Profesor-investigador, Programa Doctoral en Estudios del Desarrollo, Universidad Autónoma de Zacatecas, México.

** Profesor, Departamento de Economía, Universidad Autónoma de Zacatecas, México. 
Institucionesy tecnología como factores clave en los proyectos nacionales del desarrollo J ames M artín Cypher - A ldo A lejandro Pérez-Estcatel

\section{Resumen}

La ausencia de proyectos nacionales que permitan institucionalizar las capacidades innovadoras endógenas en América Latina ha constituido un impedimento estructural crítico al desarrollo. Se presenta en este artículo un análisis de los temas relacionados con la tecnología y el desarrollo desde una perspectiva heterodoxa. Gran parte de las naciones abandonaron sus esfuerzos incipientes por desarrollar un grado de autonomía tecnológica en contraste con los emprendimientos arrancados durante el periodo de la industrialización dirigida por el Estado. Este artículo hace hincapié en las políticas tecnológicas montadas durante este periodo y las prospectivas actuales. Para anclar el trabajo, presentamos un análisis comparativo entre los casos dimétricos de México y Brasil, enmarcado en las estructuras institucionales generadas por el poder económico y la ideología dominante, siendo los factores determinantes en la formulación de las políticas nacionales de ciencia y tecnología.

Palabras clave: instituciones, ISI, Sistema Nacional de Innovación, industrialización, Brasil, México.

Clasificación JEL: B50, F59, 032, 014, N16, N26

\section{Abstract}

The absence of national projects that have attempted to institutionalize endogenous innovation capacities in Latin America has constituted a critical structural impediment to development. This article presents an analysis of themes relating to technology and development from a heterodox perspective. A large number of nations have abandoned important incipient efforts to promote a degree of technological autonomy as was undertaken during the period of state- led industrialization. This article emphasizes technology policy during the state-led era and its current possibilities. In order to ground this effort, we present a comparative analysis contrasting the diametric cases of M exico and Brazil. We focus on national institutional structures, such as the prevailing ideology and the economic power structure, since these are the most decisive factors in the formulation of national policies governing national technological development.

Keywords: institutions, ISI, National innovation System, industrialization, Brazil, Mexico.

JEL Classification: B50, F59, 032, 014, N16, N26 


\section{INTRODUCCIÓN}

El objetivo de presente trabajo es mostrar por medio de un análisis empírico-históricocomparativo las estructuras y trabas institucionales de Brasil y México en torno a sus políticas de fomento y de ciencia y tecnología. En este trabajo se sostiene como hipótesis que los proyectos de desarrollo endógeno viables requieren un profundo cambio estructural/institucional, especialmente en la cristalización de un Estado desarrollista y la formación de un sistema nacional de innovación. Es decir, que estos países requieren un proyecto nacional de desarrollo como hilo conductor de la política industrial dinámica, ejemplo los casos más notables de Asia (i.e. Japón, Corea, Taiwán y ahora China), en donde hay estrategias para promover sectores lideres basados en el mejoramiento sostenible de las capacidades tecnológicas en la esfera de producción (Hira 2007, p. 53-130). El primer apartado de este documento se centra en el enfoque institucional heterodoxo -en donde el andamiaje no está formado por los preceptos analíticos del individualismo metodológico sin (1) tiempo, (2) espacio, (3) procesos evolutivos o(4) contexto histórico institucional- como es el caso de la variante neoclásica. Abogamos por un examen intensivo de tales fenómenos socialescomo fueron empleados por los pensadores institucionalistas $y$ estructuralistas; T. Veblen, G. Hodgsony C. Furtado (Cypher 2012; Da Motta \& Albuquerque 2007; Hodgson 2001, p. 3 40, p. 330-345; Hodgson 2006; Szmrecsányi 2005). El segundo apartado analiza críticamente el período de las estrategias de desarrollo autónomo, centrándose en el período de la industrialización por sustitución de importaciones (ISI) y en los desarrollos 
teóricos de la escuela latinoamericana estructuralista. Se destacan aquí las intervenciones de la CEPAL y sus esfuerzos para ofrecer una nueva interpretación de la legacía de América Latina en el área de tecnología. En contraste con la "leyenda negra" dominante sobre el supuesto "agotamiento" de las políticas industriales de este periodo, incorporamos nuevos índices de los estándares de vida y documentación empírica sobre el incipiente desarrollo tecnológico para reevaluar el desarrollo de América Latina antes de la etapa neoliberal vigente. En el tercer apartado se introduce el tema contemporáneo del sistema nacional de innovación (SNI) y a continuación se centra en un breve análisis de las dos formaciones nacionales contrastantes, México y Brasil, los dos países más grandes de América Latina en términos del desarrollo de sus capacidades tecnológicas.

\section{LA FORMACIÓN DE LAS INSTI- TUCIONES EN AMÉRICA LATINA}

Las instituciones de América Latina se forjaron en el siglo XVI en un momento histórico en el que los elementos depredadores rentistas del feudalismo español se encontraban en plena vigencia. El desprecio por el trabajo humano y el desdén de la cultura de uso de herramientas que rodea y nutre a los procesos de trabajo -sellos del imperio español- fueron trasladados e integrados en América Latina (Leonard, 2003; Mahoney 2003; Street 1981; Worchester 2003). Entre los factores más críticos que desencadenaron un proceso adverso de dependencia del sendero en América Latina, debemos destacar: "La indiferencia, desdén y hostilidad hacia el método científico de exploración y curiosidad y verificación que fueron indicadores del imperio español..." (Leonard 20003, p. 81). Según este investigador, la ausencia de instituciones fuertes para incubar la ciencia y tecnología son parte de una "herencia intelectual de la Edad Media que fue pasado virtualmente intacto a América Hispánica dejando en la región un "concepto autoritario de la verdad" asî explicando "en gran medida la ausencia relativa de las ciencias experimentales" (Leonard 2003, p. 82).

Según los institucionalistas, el proceso evolutivo de una sociedad podría ser analizado desde el lado de factores "ceremoniales" -las fuerzas y factores sociales que inhiben el cambio y consolidan aún más el estatus quo de la estructura del poder económico-social-y, por contraste, desde el lado de las fuerzas y factores progresistas que impulsan el cambio tecnológico e institucional (llamado el instrumentalismo). En la tensión dicotómica entre el ceremonialismo y el instrumentalismo, (como argumentaron los institucionalistas T. Veblen y C. Ayres) el ceremonialismo a menudo dominó, subvalorando el dinamismo tecnológico, socavando así las posibilidades del "desarrollo desde dentro", según Osvaldo Sunkel (Ayres 1995; Sunkel 1989; Sunkel 1990). América Latina (AL) ha luchado durante siglos con una serie de 
instituciones relativamente inmutables, en el que la 'forma predominante de hacer las cosas', siguió sin mayor reto. La porción de la sociedad comprometida en el mantenimiento y la perpetuación de habilidades de las artes tecnológicas, era pequeña y marginada. El espíritu rentista de corto plazo que floreció en la industria minera en el comienzo de la era colonial impregnó la sociedad española en la medida en que la propia comunidad industrial de España fue abandonada por efecto de la maldición de los recursos (es decir, la afluencia de capital liquido desde Perú y México) mientras que las de Flandes, Francia, Holanda e Inglaterra florecieron (Stein\&Stein, 1970, p. 5-19). Estos países fueron proveedores de mercancías manufacturadas para España y su imperio -frecuentemente producido con materias primas provenientes de España o de sus colonias (Romano \&Carmagnani 1999, p. 204-233; Stein \& Stein 1970, p. 5-19)-. Por ejemplo, en la construcción naval para mover mercancías en la ruta entre España y las Américas, en el período 1717-1778, casi tres cuartos de la fabricación de estas naves tuvieron sus orígenes en los astilleros de Europa afuera de España y sus colonias (Romano \& Carmagnani 1999, p. 231).

Las ganancias fáciles y rápidas fueronla esencia de unas economías de exportación agro-mineras de América Latina en el siglo XIX, que disfrutaron durante un período considerable los auges o incrementos del comercio y particularmente por el mejoramiento de los términos de intercambio del ingreso, como Argentinay Colombia (sobre todo) después de la primera guerra mundial (Bulmer-Thomas 1994, p. 81) ${ }^{1}$. Poniendo el periodo $1870-$ 1874 como base $(=100)$ y $1925-1929$ como límite, el volumen de las exportaciones de los ocho países más grandes se multiplicaron, en promedio, casi por 10 veces. Pero, fueron variaciones notables: en Colombia las exportaciones multiplicaron casi por 30 veces, Cuba por 18, Argentina por 16 y Perú por 12 (Bértola \& Ocampo, 2012, p. 93) 2 .

\footnotetext{
Los términos de intercambio de ingreso-siendo los términos del intercambio del trueque neto multiplicado por el volumen de exportaciones-, calculan la capacidad de importar. Los términos del intercambio de trueque neto son, normalmente, definidos como el índice de los precios de productos exportados dividido por un índice de los precios de bienes importados, tomando en cuenta la tendencia entre el coeficiente del año de base y el año límite (por ejemplo 1870 vs. 1920), sin referencia de los cambios en el volumen de las exportaciones o importaciones durante las fechas examinadas.

2 El alto grado de heterogeneidad en América Latina casi da garantía a situaciones que requieren aclaración: por ejemplo, ha argumentado López que en el caso Argentino (en el curso de su auge de commoditiesentre 1875 y 1929) un segmento de los terratenientes fueron innovadores en unos de los sectores agrícolas: En el medio rural se produce una verdadera revolución, tanto en la agricultura como en la ganadería, que permite que la Argentina se constituya en una potencia exportadora mundial. En tanto, surge la industria moderna en el país, instalándose una buena cantidad de plantas que utilizaban tecnologías y escalas internacionalmente competitivas -aunque este proceso avanza poco hacia las ramas más modernas y/o intensivas en conocimientos y escala-. (López, 2006, p. 97).

"Lo más importante que queremos destacar es que al menos un segmento dentro del sector terrateniente exhibió un dinamismo innovativo y una capacidad para asumir riesgos que distan de la imagen recibida..." (López, 2006, p. 99 cursivas nuestras). Pero, a continuación, en un entorno en donde no eran (1) instituciones adecuadas para "disciplinar" o "guiar" las terratenientes y (2) condiciones para mantener un proceso cumulativo instrumental, por las fuerzas inerciasinstitucionales, el resultado general aún en el mejor de los casos, era reforzar la crítica del comportamiento del élite agro-minero: "...es factible que los herederos de aquella vanguardia innovadora, con el tiempo, se hayan convertido efectivamente en algo parecido a la imagen que del terrateniente argentino ha construido buena parte de la literatura recibida (ausentista, poco interesado en las cuestiones técnicas, amante del consumo ostentoso, etc.)" (López, 2006, p. 102).
} 
Usando los mismos años como base, estos países sufrieron, en promedio, caídas de sus términos de intercambio de trueque neto, después del periodo 19101914 con la excepción de Chile por el auge de salitre (Bértola \& Ocampo, 2012, p. 93). Cuando los términos de intercambio de esta producción primaria se deterioraron en general en los años veinte (y aún más fuertemente en los años treinta) del siglo pasado, América Latina se orientó definitivamente hacia un tipo de política industrial conocido como Industrialización por Sustitución de Importaciones (ISI) a partir del 1940(Thorp, 1991; Ffrench-Davis, Muñoz \& Palma, 1991). Durante este período, como veremos más adelante, América Latina comenzó a adquirir capacidades tecnológicas incipientes. Sin embargo, los golpes militares -orquestados, financiados e inducidos por los remanentes neo-feudales de la élite agro-minera que había sido subordinada por la nueva ola de la industrialización y por las empresas monopólicas/ oligopólicas (del 'Antiguo régimen') que se resistieron a los sindicatos influenciados por las políticas de redistribución de ingresos y a los cambios del poder institucional de la era de ISIiniciaron el fin de la ISI en el Cono Sur a partir de 1973. En esta transformación retrograda estuvieron presentes las políticas exteriores y militares de los EE. UU. , como en Brasil en 1964 (Nieto, 2006, p. 169-177; p. 247-332).
Poco después, la crisis de la deuda fomentó más la oportunidad de cambio de régimen en las naciones que todavía se orientaban por las políticas de ISI (excepto Brasil). Este cambio fue orquestado por una élite ideológicamente retrógrada que se apegó a los lineamientos del FMI y el Banco Mundial para imponer la reestructuración a través de la "austeridad" y "programas de ajuste estructural" (Cimoli \& Rovira, 2008; Cypher 1989). La era neoliberal trajo gradualmente a partir de 1973 un retorno a las estrategias de exportación agromineras a veces renombradas como exportaciones "no tradicionales" y a los modelos de ensamblado con base en mano de obra barata. En otras palabras, la "primarización" algunas veces llamada neo-extracciónismo a través de la exportación de materias primas escasamente procesadas es decir, commodities y mano de obra incorporado en los productos manufacturados, controlada por un nuevo "sistema de producción integrada a nivel global" por empresas transnacionales y los conglomerados nacionales (los grupos), que se convirtió en el modus vivendi o la nueva estructura de acumulación (Cypher, 2009; Cypher \& Delgado, 2012). No hubo, en este nuevo/ viejo modelo, espacio para procesos industriales autóctonos $\mathrm{y}$, en consecuencia, para el desarrollo de sus propias capacidades tecnológicas. 


\section{EL PERÍODO DE LA INDUSTRIA- LIZACIÓN POR SUSTITUCIÓN DE IMPORTACIONES (ISI) Y LAS INTERVENCIONES DE LA CEPAL}

Los contextos históricos son muy importantes en la formulación y comprensión de los procesos dinámicos económicos. En la controversia sobre el impacto y la eficacia de la "industrialización por sustitución de importaciones" (ISI), el mismo término se puede tomar para expresar algo que la historia demostradamente ha negado: es decir, cuando las naciones latinoamericanas llevaron a cabo un intenso período de rápida industrialización (así aumentando en el lapso 1950- 1980 la porción del PIB del sector manufacturero desde $18,4 \%$ a $25,4 \%$ ) el objetivo no era un acto mecánico de "sustitución" (ISI-horizontal o "light") para lograr un alto grado de eliminación de las importaciones de consumo de bienes no duraderos y duraderos de la cuenta corriente de la balanza de pagos (French-Davis, Muñoz \& Palma, 1991, p. 357). Al contrario, era (1) promoveruna transformación de la estructura productiva y (2) promover fuerzas autónomas nacionales y entrar en un proceso con efectos autorreforzantes de crecimiento y de desarrollo socioeconómico ${ }^{3}$. Este es un importante punto de partida en el debate sobre la eficacia de lo que convencionalmente se ha denominado ISI, dado que a lo largo de la década del setenta y principios de los años ochenta, un coro de voces en toda América Latina condenó las políticas en las cuales se sustentó el proceso de industrialización por sustitución, a pesar de los logros ampliamente alcanzados, como el crecimiento del PIB anual real en promedio de 5,2 \%, 1950-1981 (FrenchDavis, Muñoz \& Palma, 1991, p. 349). Es decir, a pesar de una abundancia de problemas,sobre todo en el caso argentino, en promedio la tasa de crecimiento real era por encima del promedio "de los principales países desarrollados" durante la llamada "Edad de Oro" (1950-1975) de los países avanzados (López, 2004, p. 352).

En este periodo fue abundantemente proclamado que el modelo ISI estaba "agotado" (Boltvinik\& Laos, 1981; Bruton, 1998). Los críticos, usando la retórica del "agotamiento", no entendieron que la industrialización dirigida por el Estado propició un esfuerzo concertado de la sociedad para construir "un modelo de organización social que tenía como objetivo principal nada menos que modificar las reglas de apropiación sobre el excedente generado

\footnotetext{
En contraste con tal modelo "desarrollista" de Brasil, en Argentina -a pesar de su equipo de asesores de alta calidaddurante un periodo pivote, el Gobierno de Frondizi (1958-1962) enfrentó (1) las fuertes divisiones entre el Estado y el sector industrial dado una legacía de desconfianza provocada por acciones anteriores durante el Gobierno de Perón, (2) las posturas tomadas de sus asesores económicos en contra su propio proyecto, (3) la ausencia de una relación enraizado entre el estado y los terratenientes, y (4) una visión restringida a un modelo "light" de ISI-horizontal. Aquellos elementos fueron claves y suficientes para negar seguimiento coherente al modelo ISI argentino que originó durante los años de la Segunda Guerra Mundial (Sikkink, 1991, p. 74-119).
} 
por el sector primario de la sociedad y de canalizarlo al financiamiento del desarrollo manufacturero" (Katz \& Kosacoff, 2003, p. 82).

Fue, entonces, un esfuerzo generalizado para la reestructuración de las sociedades enteras -esto constituyó un proceso iterativo en la construcción de una estructura social de acumulación más incluyente-. Esto, por tanto, generó grandes implicaciones en términos de la creación y distribución de ingresos. Se trató de desplazar a la estructura socioeconómica pasiva de enclave centrado en una acumulación basada en los patrones coloniales y neocoloniales de especialización primario-estático (de café, carne, trigo, etc.) por un proceso activo; un modo de acumulación, socialmente construido, con retornos para la mayoría de la población. Este proceso, incluso, fue históricamente determinado o históricamente condicionado por la Gran Depresión que congeló el comercio internacional y los flujos de capital, mientras dejó los precios de los bienes primarios en picada. Las justificaciones teóricas de la ISI se basan -en primera instancia- en la obra de Raúl Prebisch y Hans Singer sobre el deterioro de los términos de intercambio comercial de productos primarios y en el rechazo de la perspectiva ricardiana y neoclásica, a favor de un análisis que incorporó en un primer plano los patrones asimétricos de intercambio internacional (Cypher \& Dietz, 2009, 93, p. 168-180). Otros aportes teóricos de la misma envergadura fueron un grupo de pensadores de la CEPAL que juntos formularon lo que se conoce como el análisis estructuralista latinoamericano (Barón, 2012; Da Motta \& Albuquerque, 2007).

El enfoque o escuela estructuralista latinoamericana va a constituir una clara ruptura con el modo dominante de entender la naturaleza y funcionamiento de la política económica de América Latina. Hasta la década de 1920, la política económica se había sustentado en los lineamientos de la economía clásica anglosajona, a menudo llamada "liberalismo económico" -basada en las ideas extremas del laissez-faire e influenciada por Jean GustaveCourcelleSeneuil en Chile (Hirschman 1989)-. En los años veinte (o poco después) del siglo XX, América Latina hizo un cambio de paradigma con respecto a la política económica. Se encuentra en el nivel de la política un abrupto abandono de la postura pasiva del laissez-faire a favor de un enfoque activo-intervencionista y fomentadora para la construcción de la nueva política económica nacional. Vale la pena señalar que este modelo generó un rápido y sostenido crecimiento en muchos países -por ejemplo, en México-, el crecimiento anual real del PIB superó el $6,0 \%$ por año de $1940-1982$, mientras que en Brasil esta tasa fue 7,5\% entre 1948 y 1980 (Moreno-Brid \& Ros, 2010, p. 347-352; Medialdea, 2012, p. 62) ¿Por qué estos resultados fueron posibles, $\mathrm{y}$ por qué este "modelo" fue entonces bruscamente abandonado por completo? (excepto en Brasil) serán analizados en este trabajo. Sin embargo, antes de 
dedicarnos a estas cuestiones, el alejamiento desde la economía clásica anglosajona hacia el enfoque "estructuralista" merece una mayor discusión:

Se ha argumentado que el análisis estructuralista surgió, en parte, de las formulaciones desarrolladas por la escuela histórica alemana y luego utilizadas, adaptadas y aplicadas a numerosos esfuerzos nacionales de investigación de estudio de casos realizados en las Naciones Unidas por la Comisión Económica para América Latina y el Caribe (Love, 2005; Sunkel, 1989). La escuela histórica alemana centró sus estudios sobre los procesos de producción y distribución en las economías domésticas, mientras que las formulaciones anglosajonas (clásica y neoclásica) hicieron énfasis en las tensiones entre los componentes interactivos de la economía (consumidores y proveedores en competencia perfecta, la tecnología de punta disponible para todos los individuos como cualquier otra mercancía determinada por las fuerzas de un mercado libre y competitivo) y un Estado minimalista que debe de limitarse a la función esencialmente pasiva de "vigilante nocturno" -manteniendo las reglas del juego del mercado libre-. En el caso de la CEPAL, un contraste muy similar entre las formulaciones anglosajones y los de la escuela estructuralista latinoamericana, constituye el punto de partida para un trabajo reciente y extremadamente importante sobre adaptación tecnológica, durante la era de la ISI, por Jorge Katz y Bernardo Kosacoff (Katz
$\&$ Kosacoff, 2003). Como ha argumentado Hodgson en mayor detalle, su análisis comienza centrándose en lo que ellos llaman la "profunda brecha epistemológica entre una corriente de pensamiento estructuralista, que se originó en la escuela histórica alemana" y las contribuciones de los pensadores clásicos y neoclásicos británicos (Jevons, Marshall y Smith entre otros) del individualismo metodológico basado en "leyes" universales (Hodgson, 2001, p. 56-134; Katz \& Kosacoff, 2003, p. 58). Hacen hincapié en que para la escuela histórica alemana, la perspectiva con respecto al desarrollo implica
... una postura eminentemente intervencionista proveniente de la necesidad alemana de cerrar la brecha tecnológica relativa que en ese entonces mostraba [con] respecto a las mejoras prácticas productivas británicas. En función de ello, pone al Estado como agente central del cuadro de organización social, coordinado y dirigiendo las relaciones económicas individuales (Katz\&Kosacoff, 2003, p. 58).

Una síntesis de los eslabones del análisis heterodoxos ha dado como resultado que los principales determinantes del crecimiento económico de largo plazo no estén fundados en la asignación de recursos a través de las señales de precios adecuadas del mercado competitivo anglosajón, sino en "el desarrollo de sus capacidades tecnológicas propias y la creación y consolidación de nuevas 
instituciones" (Katz \& Kosacoff,2003, p. 59). En este sentido, estaposición es muy cercana a la adoptada por los institucionalistas como Hodgson y Nelson (y muchos otros autores heterodoxos citados más abajo) sobre el proceso de co-evolución en el entrelazamiento entre el avance tecnológico y la recomposición de las instituciones (Hodgson 1998, 2006; Nelson 2008, 2009). Para Nelson "Consiguiendo las reformas necesarias en la estructura económica pudiera ser una tarea aún más difícil que obtener el conocimiento científico y de ingeniería requerido para operar las tecnologías nuevas" (Nelson, 2011, p. 46). Para Hodgson, hay que poner énfasis dual sobre la dicotomía entre la "agencia humana" (protagonista, a la vez, de la dinámica tecnológica instrumental) y de las fuerzas del estatus quo e interés opuestos, es decirfuerzas inerciales y obstáculos ceremoniales, (elementos clave de la teoría de la "dependencia del sendero") enraizadas en las estructuras sociales existentes (Hodgson, 2006, p. 8)

De tal manera, la industrialización es vista como una actividad clave de una estrategia de desarrollo viable, ya que:

... en su conjunto dan forma y contenido a una vasta 'cultura' productiva e institucional que permea a lo largo de la comunidad. Tal 'cultura' -que comprende tanto saberes tecnológicos, como también capacidades de gestión empresarial y hábitos de comportamiento laboral-constituye un 'capital social' de gran importancia que condicionay a su vez es condicionado por-el sendero evolutivo por el que transita la sociedad (Katz \& Kosacoff, 2003, p. 60).

Pero, las críticas formuladas por los economistas neoclásicos sobre lo que ellos (mal) entendieron del modelo y funcionamiento de ISI, dejaron la impresión de que la ISI únicamente generó en las naciones de la periferia "agentes públicos corruptos y empresarios rentistas que sólo fueron capaces de instalar plantas productivas ineficientes, incapacitados para enfrentar el desafío de la competencia internacional" (Katz \& Kosacoff, 2003, p. 62).

Contra este estereotipo superficial, los autores de la CEPAL expusieron un gran cúmulo de evidencia para demostrar que el enfoque basado en la producción económica de la escuela histórica alemana generó resultados loables y muy prometedores en muchas naciones de América Latina. Todo esto ocurrió hasta el momento en que la industrialización dirigida por el Estado en AL fue destruida por una serie de golpes militares en el Cono Sur entre 1973-1976 o por los programas de austeridad y ajuste estructural del FMI y el Banco Mundial a principios de los años ochenta. Los resultados de la época de ISI (1940-80) para Argentina, Brasil, Chile, Colombia, México y Venezuela -los países conocido como "AL6", dado su importancia en América Latina- se presentan en las Tablas 1 y 2, abajo. 
En la Tabla 1 se muestran los resultados de los cambios en el "índice histórico de los estándares de vida" de las Naciones Unidas (siendo un índice histórico de tres variables ponderadas: ingreso por persona, anticipación de vida, tasa de alfabetización de adultos y esperanza de vida). Se puede observar que, en promedio, los mejoramientos en el índice en términos porcentuales por década fueron más fuertes entre 1940-1970, $74,5 \%$ en promedio. Dejando de lado el caso argentino, el ritmo de cambio en promedio de los cinco países entre 197080 sigue siendo fuerte, según los datos presentados en la Tabla 1. Una manera comparativa de ver los logros de los AL6 en los setenta es tomar en cuenta que la brecha entre este índice histórico (HLSI por sus siglas en inglés) y el de Estados Unidos siguió cerrándose a un ritmo de 8,7\% en esta década (Astorga, Bergés \& Valpy, 2003, p. 31). Aproximadamente en 1980 podemos marcar un punto de inflexión: a partir de esta fecha, el promedio del ritmo de mejoramiento en el HLSI por década entre 1980 y 2000 se cayó abruptamente hasta llegar a
$4,83 \%$, es decir, a un tasa de crecimiento 3.75 veces inferior de lo que fue establecido en promedio por década durante la época del ISI (1940-1980).No es claro que la relación entre "estándares de vida" se origina en el modelo ISI exclusivamente, entendido desdela postura convencional/ortodoxo en que ISI era una táctica meramente de sustitución o reemplazo de ciertos bienes simples. Pero usando el término dentro del marco teórico heterodoxo adoptado arriba por Katz y Kosocoff, en donde hay (1) un proceso evolutivo hacía una nueva cultura productiva, industrial y social (2) una reordenamiento institucional en proceso de consolidación enfocado en la construcción de un estado de bienestar, (3) un proceso de acumulación inclusivo dando espacio importante para la participación de los sindicatos, y (4) una tendencia hacía el mejoramiento de la distribución de ingreso en algunos países (como México) los resultados de la Tabla 1 parecen consistentes con los objetivos del modelo de ISI (Moreno-Brid \& Ros, 2010, p. 281) $)^{4}$.

$4 \quad$ Sin duda, este modelo tenía sus elementos débiles, como la ausencia de "un carácter extremamente selectivo" (ISIvertical) priorizando sectores selectivos con posibilidades de retornos crecientes y/o economías de escala, y su carácter "excesivamente inward oriented" -por lo menos en el caso argentino (López, 2004, 363). También era notable (en contraste con los casos exitosos de ISI-vertical en Asia) la ausencia de restricciones sobre las empresas transnacionales, en algunos países (Chang, 2003a, p. 263-267; Chang, 2003c, p. 115-117; López, 2004, p. 366). 
Instituciones y tecnología como factores clave en los proyectos nacionales del desarrollo James M artín Cypher - A ldo A lejandro Pérez-Estcatel

Tabla 1. Mejoramiento del índice histórico de los estándares de vida de la ONU

\begin{tabular}{|c|c|c|c|}
\hline País & $\% \Delta 1940-1970$ & $\% \Delta 1940-1980$ & $\% \Delta 1980-2000$ \\
\hline Argentina & 21.4 & 26.8 & 4.2 \\
Brasil & 100.0 & 132.0 & 10.3 \\
Chile & 55.0 & 70.0 & 10.3 \\
Colombia & 66.6 & 87.9 & 9.7 \\
México & 90.0 & 113.3 & 10.9 \\
Venezuela & 113.8 & 127.6 & 6.1 \\
\hline
\end{tabular}

Fuente: cálculos por los autores, basado en datos y la metodología presentado por Thorp (1998, p. 357-361) y Astorga, Bergés \& Fitzgerald (2003, p. 30) .

En la Tabla 2 se presenta una perspectiva histórica aún más larga, concentrado en un variable que encapsula el comportamiento económico de los LA6, es decir, el crecimiento anual del ingreso por persona. La medida de esta tasa de crecimiento esta mostrada en términos del concepto dela Paridad de poder adquisitivo con base en el año de 1970=100. Aquí se muestra que el comportamiento de los
LA6 bajo la ISI fue, en promedio, el doble de lo que realizaron en las cuatro décadas anteriores. Pero, aún más notable es que esta variable fue 4.5 veces por encima de lo que lograron estos países en la época neoliberal (1980-2000). Igualmente importante -en términos del bienestar de la población- la tasa de volatilidad fue menor que en los dos otros periodos marcados.

Tabla 2. Crecimiento promedio del ingreso por persona, AL6* (Paridad de poder adquisitivo, PPA 1970=100)

\begin{tabular}{|l|c|c|c|}
\hline \multicolumn{1}{|c|}{ Periodo } & $1900-1939$ & $1940-1980$ & $1980-2000$ \\
\hline $\begin{array}{l}\text { Crecimiento promedio } \\
\text { Desviación estándar } \\
\text { (volatilidad) }\end{array}$ & $1.3 \%$ & $2.7 \%$ & $0.6 \%$ \\
\hline
\end{tabular}

*AL6 = Argentina, Brasil, Chile, Colombia, México, Venezuela

Fuente: cálculos por los autores, basado en datos presentados porAstorga, Bergés y Valpy Fitzgerald (2003, p. 4-7).

Esta realidad, generalmente desconocida o poco apreciada, es menos sorprendente si se considera el hecho de que varias naciones asiáticas en vías de desarrollo fueron capaces de llevar a cabo, en gran medida sin mucha crítica o atención, las mismas políticas industriales que defendía la CEPAL durante los años 1980 y 1990. 
En efecto, es importante entender que la posición única de Brasil en el siglo XXI como una nación de América Latina que respalde y sustente las políticas de dinamismo tecnológico, tiene mucho que ver con el hecho de que los programas neoliberales fueron resistidos por una gama amplia de la sociedad, y por eso no totalmente desplegadas, en contraste con otros países de América Latina (Dahlman \& Frischtak, 1993; Giesteria, 2010).

Como se ha observado, incluso por los más reconocidos neoclásicos, el tratamiento predominante neoclásico sobre la tecnología consiste en un conjunto de supuestos extremos que representan un "libre" mercado ficticio marcado por una gama de tecnologías, completamente disponible y divisible, que todos pudieran comprar (Lall \& Teubal, 1998, p. 1371) . En un mundo así no existe la necesidad de políticas de industrialización impulsadas por el Estado, porque la tecnología de frontera en todas y cada una de las áreas de producción puede ser simplemente comprada exactamente de la forma y la cantidad necesaria. Debido a este conjunto de supuestos

... el modelo neoclásico sencillamente se cierra a la posibilidad de entender la complejidad histórica y cultural del aprendizaje tecnológico y la profunda influencia que lo institucional tiene en el sendero del aprendizaje para toda comunidad... El modelo fracasa aquí en comprender la enorme importancia que tienen otras instituciones además del mercado para dar forma al desarrollo evolutivo de la sociedad y el papel que la dimensión histórica cumple en todo esto. (Katz \& Kosacoff, 2003, p. 63).

Por "desarrollo evolutivo" y "dimensión histórica", los autores pretenden poner de relieve el hecho de que las políticas de sustitución buscaban, y lo hicieron, facilitar un proceso dinámico en el que las fuerzas productivas de la sociedad maduraran. Lo que esto significa en términos concretos en la mayor parte de América Latina en el período 1940-1970 fue que

con la expansión industrial infinidad de empresas de la región, ramas completas de actividad, regiones, fueron desarrollando una base tecnológica propia y un acervo de conocimientos empresariales y técnicos, así como calificaciones operarias, hábitos de comportamiento laboral, modos de organización de la producción, mecanismos de interacción social,... que les permitió mejorar de manera significativa la productividad relativa de factores, cerrando la brecha que originalmente las separaba del escenario internacional (Katz y Kosacoff 2003, p. 64). (Cursivas añadidas).

Esta interpretación de la ISI, tan radicalmente distinta de la interpretada por los analistas de la dependencia como de los neoclásicos que insistían en el "agotamiento" de las estrategias dirigidos 
por el Estado, se basa en un profundo conocimiento de los factores dinámicos que enflorecieron en la rápida expansión de las capacidades de producción en aquel entonces. Hacen hincapié en una serie de factores que han recibido poca atención, incluyendo el surgimiento de una amplia base productiva y empresarial de pequeñas y medianas empresas de propiedad familiar (muchos de los cuales descienden de inmigrantes europeos), la capacidad del Estado para coordinar los grandes componentes del capital para financiar y desarrollar la industria pesada a través de la creación de empresas del sector público, así como de suministro de una infraestructura necesaria.

Era notable un proceso de adaptación creativa y profundización de la base productiva industrial, enfocado en la producción endógena de maquinaria autoconstruido y equipos de capital (Katz \& Kosacoff, 2003, p. 68). Como resultado de estas prácticas, durante la llamada Edad de Oro de 1950-1973, la productividad laboral en Argentina, Brasil, Colombia, México y Perú aumentó a un ritmo mayor que en los EE.UU., (Castaldi, Cimoli, Correa \& Dosi, 2009, p. 44). Luego, a medida que estas naciones se apartaron o se vieron obligadas a abandonar las estrategias impulsadas por el Estado, los niveles de productividad cayeron ${ }^{5}$.
En el afán de condenar la industrialización dirigida por el Estado y, en particular, los esfuerzos realizados en América Latina, lo que ha sido una pérdida, argumentan Katz y Kosacoff, en un entendimiento rigoroso de los procesos prometedores microeconómicos autónomos de aprendizaje y mejoramiento tecnológico en el periodo de ISI. En el entorno dinámico de la época dirigida por el Estado, señalan que:

Numerosas compañías reaccionaron ... creando departamentos o grupos ad-hoc de ayuda técnica de planta, de ingeniería de procesos, de organización y planeamiento de la producción , etc., cuyo propósito fundamental era el de generar unidades incrementales de conocimientos tecnológicos sobre la base de mejorar el diseño del producto, los procesos productivos, la organización del trabajo, los lay-out de ingeniería, las técnicas de control de calidad, las normas de producción empleadas en planta, etc. En innumerables oportunidades dichos grupos de ingeniería acababan diseñando maquinas que luego se autofabricaban en los talleres de mantenimiento de las mismas empresas (Katz \& Kosacoff, 2003, p. 72).

\footnotetext{
La única excepción fue Chile, pero incluso en este caso los niveles de productividad en el año 2007 fueron menores en relación con los niveles que Estados Unidos reportó en 1950 cuando la ISI chilena estaba operando a un nivel muy alto.
} 
Después de haber añadido secuencialmente las capacidades tecnológicas, las empresas en Argentina, Brasil y México comenzaron a exportar primero a las naciones cercanas, y más tarde a los países de industrialización avanzada. Sin embargo, estas empresas rara vez o nunca han demostrado una vocación para las exportaciones, como ha sido común en gran parte de Asia ${ }^{6}$. Adoptando una serie de estrategias "adaptativas", en numerosos casos -especialmente en la década del sesenta- las empresas locales en gran parte de América Latina poco a poco demostraron su capacidad para cerrar algunas de las brechas tecnológicas con los países industriales avanzados. Esto fue llevado hasta el punto en que el síndrome del "exportador renuente" fue superado en muchos casos y las empresas "maduras" competitivamente pudieron exportar hasta un $20 \%$ de su producción, lo que demuestra el logro de la ventaja comparativa dinámica. En el período previo a los golpes militares que llevaron los neoliberales de corte de la Escuela de Chicago al poder en el Cono Sur:

... el gradual incremento de la capacidad tecnológica interna y el creciente aumento del grado de refinación tecnológica de muchas de estas empresas hicieron que algunas incursionaran no sólo en exportaciones de bienes finales sino que también exportaran tecnología pura por medio de plantas fabriles completas, entregadas 'llave en mano' a empresas de terceros países de la región, así como licencias de productos y/o procesos localmente diseñados y/o 'adaptados' a las condiciones domésticas de producción y/o utilización y servicios de asistencia técnica de producción a empresas de menor grado de desarrollo tecnológico (Katz \& Kosacoff, 2003, p. 76). (Cursivas propias)

Hemos presentado las conclusiones de estos autores cepalinos por la importancia de sus interpretaciones en cuanto a cualquier discusión con respecto al estado actual de atraso en las artes industriales y sobre todo porque ellos han presentado meticulosamente la documentación y el contexto que se requiere para un replanteamiento del proceso de industrialización dirigida por el Estado en América Latina. Hasta hace poco, los estudios del período de la ISI se habían centrado en el análisis neoclásico y por las formulaciones expuestas por el enfoque de la dependencia que han insistido, muy falsamente, que la ISI estaba "agotada".

\footnotetext{
6 Lo que se logró en América Latina en el período 1940-1980 no es equivalente al éxito de varias naciones de Asia, desde la década de 1950 hasta el presente. Las trayectorias históricas son distintos por varias razones incluyendo las políticas productivas asiáticas para lograr sus metas de altos volúmenes de exportación, altos niveles de inversión y, muy especialmente, la capacidad para orquestar procesos de mejoramiento.
} 
Institucionesy tecnología como factores clave en los proyectos nacionales del desarrollo James M artín Cypher - A ldo A lejandro Pérez-Estcatel

\section{SISTEMAS NACIONALES DE INNOVACIÓN}

La tarea que actualmente debe enfocar Latinoamérica es dirigir la política de desarrollo hacia el mejoramiento de su base industrial nacional, aumentando el peso de la economía en actividades de alto valor agregado. Un claro ejemplo es la política industrial que ha desplegado con éxito una amplia gama de países asiáticos en el período 1960-2012, como hemos notado. Un factor crítico, no sólo en el caso de los países asiáticos en desarrollo en el pasado reciente, sino en general, más en Europa, los EE.UU. y Japón en una época anterior, ha sido la realización de lo que los schumpeterianos se refieren como el "sistema nacional de innovación” (SNI) (Shin, 1996, p. 26-37).

De acuerdo con M. McKelvey:

El término 'sistema nacional de innovación' es un concepto amplio diseñado para centrar la atención en el proceso de creación y difusión de las innovaciones... dentro de las economías nacionales específicas. Se hace hincapié en cómo las innovaciones se introducen y se extendió en un contexto nacional, ¿por qué las economías nacionales son diferentes? y hasta cierto punto ¿por qué las innovaciones son importantes para el cambio económico?" (McKelvey, 1994, p. 366).

El enfoque del SNI rompe con una larga tendencia del pensamiento económico ortodoxo donde se asumía una relación lineal entre la ciencia y la tecnología, "en el cual el cambio tecnológico se concibe como un proceso unidireccional que va desde la investigación básica (ciencia), al surgimiento de aplicaciones prácticas (innovación)," que luego se aplica ampliamente en el proceso de producción, fomentando así la mejora de la productividad/procesos que conducen al crecimiento económico (López, 2004, p. 357-358). El enfoque heterodoxo del SNI postula que las innovaciones pueden ser de tipo social, institucional, organizativa o tecnológica. La producción y aplicación del conocimiento científico, si bien son importantes, deben compartir el mismo peso que las características nacionales relativas a los mecanismos de absorción y difusión específicos de la estructura institucional de una nación. Uno de los principales contribuyentes al cuerpo de ideas que hay detrás del sistema nacional de enfoque de la innovación ha sido Christopher Freeman. El encapsuló el concepto como "La red de instituciones de los sectores público y privado cuyas actividades e interacciones inician, importan, modifican y difunde las nuevas tecnologías" (OECD, 1997, p. 10).

En la práctica, el concepto del sistema nacional de innovación con frecuencia se expresa en términos de la red de interacciones y complementariedades entre (1) las empresas, (2) las instituciones públicas y (3) las instituciones de investigación (OCDE, 1997, p. 9). En general, las naciones de América Latina han sido incapaces de 
alcanzar la visión institucional y las capacidades necesarias para embarcarse en el camino hacia la consolidación de un sistema nacional de innovación (SNI). Construir, mantener y ampliar este sistema es una tarea de enormes proporciones en el sector industrial de las naciones más avanzada. Recientes investigaciones en el campo sugiere una limitada estrategia de corte "segunda mejor", centrada en la innovación y la transferencia de la tecnología en términos de "capacidad de absorción" y "capital social" para las naciones menos desarrolladas y no en un "verdadero sistema de innovación" (Ludnvall, Vang, Joseph \& Chainade, 2009, p. 5, 8, 1718). Según Pietrobelli y Rabellotti, "los países en desarrollo tienen una mayor necesidad de construir la base inicial de las capacidades para apoyar su industria en los procesos de aprendizaje" debido a una serie de factores condicionantes como la baja capacidad empresarial, los sistemas financieros poco profundos y en las malas redes de información (Pietrobelli \& Rabellotti, 2009, p. 217). Además,

la ciencia y las organizaciones de tecnología del sistema de innovación estudiadas a menudo en los países desarrollados, tales como universidades, laboratorios de I+D e institutos de investigación, en algunos países en desarrollo no están presentes o pueden ser inadecuados", mientras que las interconexiones entre estas instituciones y el sector productivo "son inexistentes o débiles (Pietrobelli \& Rabellotti, 2009, p. 217).
Un estudio reciente en cuatro naciones latinoamericanas corrobora fundamentalmente la anterior perspectiva, lo que sugiere que las naciones muy pequeñas, idiosincráticas (Chile, Costa Rica, Panamá y Uruguay) o naciones que carecen de la estabilidad institucional básica (Colombia), muestran una "ausencia " o un escaso desarrollo de las redes de innovación “ (Crespi \& Zúñiga, 2012, p. 281). En contraste, los resultados para Argentina son relativamente positivos. Esto es probable al legado de cambios institucionales positivos introducidos en el período de la ISI, como se analiza en el trabajo de Crespi y Zúñiga (2012, p. 212, 282). En general, señalan estos autores, los rendimientos privados y sociales para la innovación en la productividad de la mano de obra son muy altos en América Latina más altos en promedio que en los países industrializados. Sin embargo, el apoyo institucional para la innovación sigue siendo débil.

Incluso la nación más avanzada en el camino hacia la construcción de un SNI, Brasil, no ha consolidado sus beneficios. Esto, al menos, es la conclusión de Liana Carleial y Bruno Cruz donde sostienen que: "la nación tiene cada una de las partes [el sistema productivo y los productores del know-how] y no han podido reunirlos para generar las sinergias" (Carleial y Cruz, 2011, p. 22). En seguida examinamos dos situaciones actuales en cuanto las capacidades de construir un SNI en los dos países más grandes, importantes y (tal vez) más representativos de América Latina. 
Instituciones y tecnología como factores clave en los proyectos nacionales del desarrollo J ames M artín Cypher - A ldo A lejandro Pérez-Estcatel

\section{El caso de México}

Mario Cimoli, en particular, ha examinado la debilidad general y la casi ausencia de un SNI en México. Cimoli señala que los elementos limitados de lo que generosamente podría denominarse SNI mexicano están estancados, la brecha entre las capacidades tecnológicas de México y los de las naciones que operan en las fronteras del desarrollo tecnológico, es cada vez mayor. El poco avance tecnológico que se produce en México está en función de la tecnología importada, incorporada en maquinaria y equipo (Cimoli, 2000, p. 285-292). En cuanto a los efectos de encadenamientos a la Hirschman, Cimoli considera que "cada vez más se sustituyen por un proceso de integración internacional" (Cimoli, 2000, p. 285). Un menor grado de conocimiento y de la difusión tecnológica se deben a que, "junto con este proceso, podemos ver una dramática pérdida de articulación en los vínculos existentes y sus proveedores nacionales de insumos" (Cimoli 2000, 285).

La dinámica económica de México en gran medida se vio influida y guiada a través de intervenciones de política importantes que anteriormente hemos denominado "industrialización dirigida por el Estado" durante el periodo 1940-1982. Esto fue seguido por un período complejo de transición, 1983-1993, que llevó a la incorporación plena de las políticas neoliberales y la adopción de una estrategia nacional tecnológica pasiva. Durante el período de industrialización dirigida por el Estado se produjo un aumento general tanto en los vínculos como en la creación de una "capacidad de aprendizaje tecnológico independiente" (CATI) (Pérez-Escatel, 2012).

A pesar de que los gobiernos no invirtieron ni crearon las instituciones capaces de crear las condiciones para que se dieran procesos de aprendizaje -del tipo que la literatura relata en las economías asiáticas-, se ha encontrado que en muchas empresas y sectores de la manufactura mexicana estaban presentes algunos procesos de aprendizaje en el periodo de ISI (PérezEscatel, 2012, p. 112).

Adquirir y construir una CATI es un paso inicial que puede, en virtud de las políticas adecuadas, llevar a la creación de las "capacidades tecnológicas". México, por supuesto, nunca se acercó a este nivel de desarrollo tecnológico. Un CATI implica la apropiación de las tecnologías existentes y su adaptación a las condiciones de la economía nacional. Esto significa que una nación está logrando cierto grado de autonomía tecnológica limitada. Cuando el proceso de industrialización dirigida por el Estado enfrenta una crisis de continuidad, las políticas industriales "ligeras" o "superficiales" de sustitución de importaciones pudieron haber sido transformados en formas más profundas en la industrialización dirigida por el Estado. En México, sin embargo, dichas políticas se tambalearon en 1981-82. Llegando a tal punto que las naciones de Asia tuvieron que cambiaron de 
estrategia (puntos de inflexión), pero en su caso México se mantuvo cerrado en la aplicación de políticas industriales poco profundas (a veces aplicadas, a medidas, por unos cuantos estados industriales de México).

En términos de capacidades tecnológicas, Mario Capdevielle encontró que el $80 \%$ de la industria manufacturera mexicana se dedica a actividades "maduras" de producción donde poco desarrollo tecnológico subyacente se produce (Capdevielle, 2003, p. 455). Y la probabilidad de desarrollos tecnológicos 0 los efectos indirectos son bajos o nulos en estas áreas dominantes. Capdevielle reveló que las empresas mexicanas manufactureras que operan en los tramos inferiores de cambio tecnológico se mantuvieron restringidas a los procesos de adaptación de las tecnologías existentes (Capdevielle 2003, p. 456). Mientras que el modelo neoliberal se respalda sobre la expansión de la inversión extranjera directa (IED), Capdevielle señala que en promedio las empresas pequeñas y medianas gastaron más en investigación y desarrollo (I+D) como porcentaje de su ventas que las grandes empresas mexicanas (Capdevielle 2003, p. 459). En comparación, utilizando la relación de los gastos de $\mathrm{I}+\mathrm{D} /$ ventas totales como un proxy para el dinamismo tecnológico, las empresas estadounidenses gastaron más de cinco veces que lo hicieron las empresas mexicanas (Capdevielle, 2003, p. 459).
Hay, sin embargo, algunas áreas de la producción en la industria manufacturera mexicana que tienen un componente científico o una "base científica", lo que sugiere la posibilidad de efectos dinámicos de la tecnología. Sin embargo, estas zonas de cultivo de "oportunidades tecnológicas" no necesariamente son ahora más notable que lo fueron durante el último decenio de la industrialización dirigida por el Estado (Capdevielle, 2003, p. 455). A este respecto Pérez-Escatel y Pérez (2009) muestran que las empresas manufactureras mexicanas no mejoraron sus capacidades tecnológicas con la apertura comercial. Por otro lado, las empresas "exitosas" primero desarrollaron sus capacidades tecnológicas en la época ISI y esto les permitió competir a nivel internacional en el periodo de liberación comercial. De acuerdo con un estudio realizado por Alma López y Roberto Rocha, ha habido una "notable erosión institucional", desde la época de ISI a la actual era neoliberal en términos de la tecnológica nacional/política científica (Rocha \& López, 2003, p. 126). En la época anterior dicha política estaba dirigida a la formación y el desarrollo de las capacidades tecnológicas. En la época actual los gastos principalmente se han centrado sobre un enclave teórico o investigación científica no aplicada, donde los esfuerzos del gobierno han mostrado una consistente falta de continuidad y mecanismos de retroalimentación. Dentro del aparato del Estado, el gasto público en la ciencia ha sido en gran parte separada y sin coordinación con los esfuerzos y programas de otros organismos del Estado. 
Los conglomerados mexicanos han puesto grandes énfasis en los aspectos superficiales de la competitividad, tales como control de calidad, marketing y técnicas de contabilidad. De este modo, las capacidad de hacer avances en los aspectos de la producción más ligeras en algunas empresas, que si invirtieron en $\mathrm{I}+\mathrm{D}$, mejoraron notablemente hasta principios de 1990. Pero, después éstas también se han estancado. Los elementos del sistema nacional de innovación mexicano que habían iniciado en la era de la industrialización dirigida por el Estado han entrado en decadencia, los grandes grupos o conglomerados, no podían acogerse a la multiplicidad de efectos externos positivos que gozan las empresas transnacionales instaladas en México, donde sus sistemas de producción están en gran medida en función de los sistemas nacionales de innovación en su país de origen.

Para concluir con esta breve sección sobre México, hay que considerar dos esfuerzos recientes para entender la dinámica tecnológica institucional en México. El primero - por Dutrénit, Puchet y Teubal (2011)-, basado en una metodología institucional/evolucionista, se enfoca en las posibilidades productivas creadas por el aumento en las capacidades de la fuerza de trabajo científico. El segundo es un análisis de un caso concreto -la nueva industria aeroespacial- por Martínez Romero (2011). Dutrénit plantea que la construcción de un SNI es un proceso"coevolutivo" entre (1) el aumento de las capacidades de los investigadores y profesores quienes, potencialmente, son agentes cruciales en el proceso de la transformación de las fuerzas tecnológicas para la producción industrial y (2) la innovación, siendo una función del tamaño (cuantitativo y cualitativo) de los ingenieros y técnicos involucrado en actividades innovadoras quienes, también, tienen el poder de transformar las capacidades tecnológicas para la producción industrial. En estos términos, se ha generado un aumento considerable de capacidades. Por ejemplo, entre 2000 y 2005 el número de los investigadores incluido en los dos grupos se duplicó. Pero, con una cifra total en 2005 de solamente 83,000 personas, los autores concluyeron que (en comparación con otros países que tienen un SNI establecido) México queda muy lejos de establecer una "masa crítica" en cuanto a las capacidades tecnológicas de la fuerza del trabajo (Dutrénit, Puchet \& Teubal, 2011, p. 60). También estos autores enfatizaron ciertos cambios institucionales/legales que permitieron un giro hacia mecanismos de apoyo emergentes por parte del Estado, como el Programa Especial para Ciencia y Tecnología 2001-2006 y su seguimiento institucional para 2007-2012 (Dutrénit, Puchet \& Teubal, 2011, p. 59-60). Pero estos cambios, quizás llenos de posibilidades, no han sido apoyados por el entorno nacional neoliberal. Por parte del Estado, se disminuyeron los gastos agregados en ciencia y tecnología (respecto el PIB), mientras que los gastos del sector privado han aumentado. 
Entonces, México ha quedado con una cifra para gastos en $\mathrm{C}$ y $\mathrm{T}$ entre 0,3 y $0,5 \%$ del PIB en las últimas décadas -un nivel muy lejos de losestablecidos por los países que tienen un SNI desarrollado-.

Como ha sido el caso en otras ocasiones, los voceros del gobierno mexicano y los promotores de una nueva imagen para México han tratado de aprovechar la oportunidad presentada por el crecimiento de la industria aeroespacial para asegurar que México ya ha llegado a un nivel muy alto en capacidades tecnológicas en el sector manufacturero (Martínez,2011, p. 303).

A partir del noventa, en los estados mexicanos de Querétaro y Chihuahua, los encargados de formular políticas del desarrollo económico para los estados (las Secretarías del Desarrollo Económico) iniciaron programas de apoyo para la industria aeroespacial, como la creación del primer parque industrial aeroespacial $y$ una universidad aeroespacial en Querétaro y un instituto de entrenamiento técnico-CENALTEC- en Chihuahua. En abril del 2011 estaban en operación 232 empresas aeroespaciales -un aumento considerable desde 2005, cuando eran 61 (Martínez, 2011, p. 306). El empleo directo creció de 10,000 personas en 2005 hasta 27,000 en 2010 y las exportaciones llegaron a $\$ 3.5$ mil millones de dólares (Martínez, 2011, p. 306). Pero el sector público no ha ofrecido apoyos considerables para proyectos de I+D: cuando es necesario dar apoyo por mil millones de dólares para promover la producción de turbinas, colectivamente los 25 proyectos de $\mathrm{I}+\mathrm{D}$ en el sector recibieron solamente $\$ 3.5$ millones de dólares en 2010 (Martínez, 2011, p. 306).

Los llamados clusters aeroespaciales en México no coinciden con la idea de Marshall sobre los "distritos industriales" intensivos en externalidades. En el caso de México, las innovaciones, la maquinaria y los sistemas de producción son elementos importados; siendo el papel de México de abastecer mano de obra calificada, infraestructura adecuada (incluyendo entrenamiento de la fuerza de trabajo) y poco más. Es decir, en vez de un distrito como descubrió Marshall, hay un sistema llamado "plataforma satélite" que, realmente, es un enclave en donde los procesos de producción e innovación de alto valor agregado son realizados normalmente afuera de México (Martínez, 2011, p. 307). En este modelo de producción, el mercado interno de México no cuenta. Según los resultados de la encuesta de 2009, el papel de las empresas locales aeroespaciales en la creación de fuentes de conocimiento fue cero, mientras que las empresas matrices fueron las proveedoras de $70 \%$ del conocimiento (Martínez, 2011, p. 310). Al respecto de las razones de ubicación en México, la respuesta más común, cubriendo $80 \%$ de los encuestados, fue el bajo costo de operación (Martínez, 2011, 312). De tal manera, los factores que explican el auge de plantas subsidiarias de las transnacionales aeroespaciales son precisamente los factores que explican la 
ubicación de miles de fábricas de tipo maquiladora a lo largo de México.

$\mathrm{Ni}$ al nivel micro (la industria aeroespacial) ni al macro, ni en términos de cambios estructurales socioeconómicos, ni en el ámbito de la política económica, podemos documentar una tendencia fuerte y contundente hacía una estrategia de fomentar un SNI viable en la industria aeroespacial, ni tampoco, en términos de la creación de una "masa crítica" de investigadores. En un estudio más sistemático sobre el tema del SNI en México, los autores concluyeron que los problemas claves para México son enfrentar las debilidades abrumadoras en la asignación del presupuesto del Estado hacía la $\mathrm{C}$ y $\mathrm{T}$, dado que no hay coherencia (al nivel nacional o regional) en las prioridades, objetivos y entendimientos para incubar un SNI (Dutrénit, Capdeville, Corona, Puchet, Santiago \& Vera-Cruz, 2010, p. 336).

Entre las "fallas sistémicas" que impidan la construcción de un SNI viable son (1) una infraestructura insuficiente por la falta de la priorización en "el abastamiento de energía... [las] instalaciones de prueba, [el] sistema de educación y entrenamiento [y el] equipamiento científico y tecnológico" (aunque a partir del 2007 se ha dado cierto mejoramiento); (2) "la escasez y la inadecuada asignación de recursos" en una forma instrumental-funcional, dado que estas asignaciones se deciden de acuerdo a "las cuotas de poder" económico y político en la sociedad; (3) las políticas horizontales que asumen que hay incentivos suficientes para iniciar un proceso virtuoso en el mejoramiento de las capacidades tecnológicas, mientras que las empresas siguen con sus tácticas cortoplacistas en la búsqueda de rentas y con una dependencia creciente en la importación de tecnología (Dutrénit et al., 2010, p. 337-339). Otra falla profunda son las relaciones complementarias y simbióticas entre las empresas, las universidades, las agencias del gobierno y los centros públicos de investigación para "proporcionar el aprendizaje interactivo" y generar las externalidades (que son los elementos claves e intrínsecos de un SNI) son débiles, si no carentes (Dutrénit et al., 2010, p. 339-340).

No obstante, hay gente influyente que abogan por una política industrial y el abandono de las políticas oportunistas con retornos decrecientes del modelo liderado por las exportaciones que fue impuesto en los años ochenta (De Maria, Campos, Domínguez \& Brown 2012). Es decir, hay una disputa de "baja intensidad" sobre la continuidad de la política económica dominante. Pero hay poderes establecidos del sistema actual (basado en la exportación de manufacturas con mano de obra barata) que gozan de una buena posición y permite cierta comodidad a la clase dominante en México bajo la situación actual de "dependencia adversa del sendero" (Cypher \& Delgado, 2012). Llama mucho la atención el contraste de esta situación con la de Brasil. 


\section{El caso de Brasil}

Durante el Gobierno del presidente Kubitschek (1956-60) se hizo un esfuerzo concertado para apoyar la rápida industrialización, el sector industrial creció un $262 \%$. Se utilizó una política de puertas abiertas para la adquisición de tecnología y la dominancia de capital extranjero fue muy alta $(100 \%$ de los dueños de las plantas en autos, el $50 \%$ en bienes de capital). El mercado doméstico fue frecuentemente reservado para inversionistas extranjeros quienes pudieran recibir subsidios, como otro incentivo: "al mismo tiempo, sin embargo, se dieron pasos significativos en el área de la ciencia y la tecnología. El Consejo Nacional de Investigaciones ( $\mathrm{CNPq})$ se estableció en 1951 para promover la investigación en todas las áreas" (Dalhman \& Frischtak, 1993, p. 417). En 1968, en el marco del plan de desarrollo, por primera vez el Estado define un proyecto nacional específico de ciencia y tecnología (CyT), como resultado de la comprensión del gobierno militar en CyT, el cual era vital para la creación del poder nacional.

Desde 1973-1985 tres planes básicos fueron publicados. El segundo (19751979) hizo hincapié en la debilidad de las empresas nacionales y el creciente peso de las empresas transnacionales como principales barreras para el desarrollo tecnológico autónomo. El tercer plan básico señaló las deficiencias en capacidades tecnológicas de las empresas domésticas, aumentando los fondos en CyT. Para la industria, a partir de 1972, el acto más significativo fue la creación de la Secretaría de Tecnología Industrial (STI) del Ministerio de Comercio. El STI se centró en

(1) la realización de programas de I+D a través de sus propios institutos, (2) la financiación para el desarrollo tecnológico en las empresas públicas y privadas y de tecnologías específicas, (3) el suministro de información tecnológica a las empresas, (4) la administración de un sistema de derechos de propiedad intelectual ... y la regulación de las transferencias de tecnología ....(Dalhman \& Frischtak, 1993 p. 419).

A pesar del apoyo federal dedicado a la ciencia, la tecnología y la innovación:

La base industrial grande $\mathrm{y}$ diversificada de Brasil -resultado de un largo proceso de sustitución de importaciones- no es lo suficientemente 'profunda'. Relativamente pocas empresas están en condiciones de ampliar la cuota de mercado sobre la base de las ganancias sustanciales en la productividad, la mejora continua de la calidad, fiabilidad del producto o el desarrollo de nuevos diseños. La mayoría de los productores han basado su posición en el mercado sobre la explotación extensiva de los recursos naturales y en mano de obra barata..." (Dalhman \& Frischtak, 1993, p. 425). 
A lo largo del período de la ISI, pocas empresas participaron en I+D: 1,050 en 1976-77, 780 durante la recesión de 198183, y 1,090 en 1985. En 1983 el $63 \%$ de estos gastos de I+D fueron realizadas por empresas de propiedad estatal, con sólo 25 grupos del sector privado contando por $17,4 \%$. El número de investigadores fue sólo en un ratio de 1/10 comparado con el nivel de los países desarrollados (Dalhman \& Frischtak, 1993, p. 415).

Durante el período antes señalado, Brasil se centró en una política de innovación, con resultados modestos, lo que ilustra el complejo desafío de avanzar hacia un SNI. En los años 1970 y 1980:

entre $80-90 \%$ de las actividades de I+D han sido llevadas a cabo por el gobierno. Por desgracia, la dispesión de los esfuerzos en I+D del sector público y los vínculos entre los institutos de I+D del sector público y el sector privado han sido débiles, lo que ha significado que los servicios tecnológicos no han estado a la par con la asignación del volumen de recursos del sector público a las actividades tecnológicas (Dalhman \& Frischtak, 1993, p. 414).

Según un reporte más reciente -la encuesta amplia de "PINTEC" [encuesta brasilera de innovación tecnológica]- los esfuerzos de Brasil para promover las capacidades tecnológicas endógenas sugiere que Brasil ha hecho modestos, pero prometedores avances: el estudio del año 2000 de PINTEC, el primero de su tipo, encuestó a un universo de 72,000 empresas industriales con 10 o más empleados, el muestreo de 11,000 empresas. El estudio encontró que el $31,5 \%$ de todas las empresas declaró haber introducido algún tipo de innovaciones tecnológicas entre 1998 y 2000, 7.400 empresas han realizado I+D en 2000. Cuarenta y tres por ciento de estas empresas hizo I+D sobre una base continua, mientras que el resto $(57,1 \%)$ los hizo de una forma ocasional.

De ninguna manera son las actividades industriales brasileñas en $\mathrm{I}+\mathrm{D}$ insignificantes. Representan el 32,7\% del mercado interno en $\mathrm{I}+\mathrm{D}$. El resto en $\mathrm{I}+\mathrm{D}$ se lleva a cabo por instituciones académicas públicas o privadas instituciones y centros de investigación. Aunque esta proporción se encuentra por debajo de lo que se ha encontrado en los países desarrollados, donde se trata de superar el $75 \%$ en los Estados Unidos, los esfuerzos llevados a cabo internamente por las empresas en $\mathrm{I}+\mathrm{D}$ no puede considerarse irrelevante, ya que define el nivel tecnológico del sector industrial brasileño (Furtado \& Carvalho, 2005, p. 1).

No obstante, durante la década del noventa el cambio hacia la austeridad, el "neoliberalismo atenuado" y la desaceleración de las empresas nacionales facilitaron una amplia onda de fusiones y adquisiciones por parte de las empresas transnacionales. Esta década parcialmente socavó el crecimiento de los desembolsos (en cifras reales) realizados 
por el Estado en el conjunto de ciencia y tecnología. En 2004 los gastos fueron sustancialmente más bajos que el nivel de 1991, aunque la tendencia general fue una parálisis en el rubro (Amann, 2009, p. 201). Incluyendo la I+D y otros rubros, los gastos públicos totales en CyT $(88 \%$ de total nacional) fueron un modesto $1,2 \%$ del PIB en 2000 (Amann, 2009, p. 202).

Sin embargo, estudios llevados a cabo en períodos relativamente breves sobre el sector manufacturero de Brasil por parte de Correa (1998-2000), De Negri (20002003) y Raffo (1998-2000) muestran resultados muy positivos para la productividad laboral como resultado de los gastos en I+D; mientras que Godhuys (2000-2003)no logró encontrar una relación entre los gastos en $\mathrm{I}+\mathrm{D}$ y la innovación o la productividad total de factores (Crespi \& Zúñiga, 2012, p. 281). Aunque lejos de ser una afirmación definitiva -debido a los cortos períodos examinados, que fueron condicionadas por la crisis financiera asiática de 1997, la especulación contra el contagio de la moneda brasileña y la masiva fuga de capitales durante y después del ciclo de la elección presidencial de 2002- estos resultados muestran una creciente vinculación entre los sectores público y privado para aprovechar los beneficios potenciales más rápidamente posible de $\mathrm{I}+\mathrm{D}$.

Más allá del giro "neoliberal atenuado" de la década del noventa, el énfasis de Brasil desde la década del cuarenta en CyT, la política industrial y la ISI, ha sido crucial en la creación de una serie de “campeones nacionales", como Embraer (aeronáutica), Petrobras (petróleo), Odebrecht (construcción) y Vale (basada en los recursos de procesamiento). Estas empresas y muchas otras, se han convertido en importantes corporaciones transnacionales brasileñas comprometidos tanto con la I+D endógena y la cooperación con el Estado para ubicarlas en la vanguardia del desarrollo de innovaciones de productos y procesos de tecnología (Amann, 2009, p. 204-215). Los estudios de casos de estas empresas muestran "cómo las competencias establecidas en el ámbito nacional en el marco de una estrategia orientada hacia el exterior más tarde se puede implementar con buenos resultados a nivel internacional" (Amann, 2009, p. 215). El acontecimiento más importante de la década de 1990 en la base industrial brasileña fue el severo proceso de reestructuración y "modernización intensa" que se tradujo en un espectacular aumento de la productividad (Castro, 2009, p. 259). Con dificultad, Brasil conservó su diversidad industrial heredada del período de la ISI y de algunos sectores -como la importante industria metal-mecánica- que fue fortalecida (Castro, 2009, p. 259).

El esfuerzo actual de Brasil para desarrollar las capacidades endógenas, señala Glauco Arbix, es a la vez distinto del modelo de laissez-faire de los años 1990 y del modelo asiático (Arbix, 2009). Las estrategias de desregulación y de liberación de mercados, predominantes en la década de 1990, están siendo desplazados por una estrategia de 
"desarrollo a través de la innovación". La política nacional de CyT ha ido evolucionando hacia una mayor capacidad productiva mediante la creación de instituciones clave como la CNDI [Consejo Nacional para el Desarrollo Industrial] y de ABDI [Agencia Brasileña de Desarrollo Industrial], así como a través de la revitalización de las entidades establecidas como FINEP [Financiadora de Estudios y Proyectos (científicos)] y el BNDES (el Banco Nacional de Desarrollo). Brasil ha aumentado rápidamente el número de doctores, en gran medida a través de sus propias instituciones fuertes de posgrado. Este mayor énfasis en la capacidad humana se ha reflejado en un aumento de las publicaciones científicas -duplicadas entre 2000-2007-. El financiamiento para el Plan de Ciencia, Tecnología e Innovación se ha incrementado en un $600 \%$ desde 2000 hasta 2010 . El gasto en I+D como porcentaje del PIB alcanzó el 1,7\% del PIB en 2010 -más del 35\% por encima del nivel de 2004 y 3 a 5 veces más el previsto para México (Ministério da Ciência e Tecnologia de 2011, Tabla 2.1.2)-. Brasil superó los niveles de I+D/ PIB equivalente a los de China en 2010. Como un elemento crucial en el desarrollo de Brasil, el banco gigante de desarrollo BNDES ha disfrutado recientemente de un aumento anual de financiación de 10-12\% que permite a la venerable institución ser la punta de lanza de proyectos de política industrial en áreas estratégicas. El Plan de Acción 2007-2010 de Ciencia, Tecnología e
Innovación prevé un incremento del 27\% en el sector privado en $\mathrm{I}+\mathrm{D}$ como porcentaje del PIB, casi el doble de la cuota total (público y privado) para México. El Estado brasileño busca recuperar su rol promotor/coordinador, haciendo hincapié en asociaciones público-privadas. Este paso se centrará en la mejora de una red nacional de proveedores de pequeñas y medianas empresas, la introducción de nuevas formas de apoyo, seguimiento y consulta. Cómo este tipo de iniciativas políticas se conectará con las entidades de propiedad extranjera, un tema crucial, no es evidente.

La importancia más amplia de Brasil para desarrollar las capacidades de innovación endógenas se va a ubicar en términos de transferibilidad. Las "lecciones" de rápido desarrollo económico de Asia no son desconocidas en América Latina. El concepto de "transferibilidad", sin embargo, no es generalmente aceptado. De este modo, los responsables de la política latinoamericana han buscado refugio en una variedad de argumentos, tales como que los logros de Asia son particularmente atribuibles a los "valores asiáticos", para rechazar la posibilidad de la "transferibilidad" (Chang, 2003 a , 2003 , $2003^{c}$ ). Dejando de lado estas cuestiones, si Brasil logra un cierto grado de éxito en su campaña para conseguir un aumento en sus propias capacidades de innovación (o más), la cuestión de la "transferibilidad" se va a reconfigurar en América Latina. Como tal, la lección brasileña tendrá la prominencia particular en varias 
de las naciones más grandes de América Latina.

Después de aproximadamente tres décadas de políticas neoliberales nihilistas promovidas por los devotos de la Escuela de Chicago en América Latina, ha quedado muy poco del sistema construido en la etapa ISI. Es evidente que, en términos conceptuales, la formulación del concepto de SNI es un gran avance. También se plantea la posición para un cambio institucional: Brasil muestra algunos indicios para avanzar en el logro de esta nueva institucionalidad, a pesar de los problemas de coordinación, como se señaló anteriormente en Carleial y Cruz, que no se han resuelto por completo. Por otra parte, solo 6,000 de 90,000 empresas industriales invierten en $\mathrm{I}+\mathrm{D}$, estos gastos representan solo el $0,6 \%$ del total anual de estas empresas (Arbix \& De Negri, 2009, p. 334-335). La transformación institucional en Brasil solo será posible con una nueva cultura industrial/empresarial y el compromiso de construir un sistema de producción orientado en la innovación incrustado en prácticas institucionales como resultado de las políticas desarrollistas en curso, a menudo dirigidos por el Ministério da Ciência e Tecnologia diseñadas para facilitar esta transformación.

Mientras tanto, parece que el resto de América Latina está deslizándose hacia abajo en una espiral de "primarización" que muestra signos preocupantes de "lockin"-los efectos adversos de la dependencia del sendero- (Cypher, 2009).
Sin embargo, como Katz y Kosacoff han demostrado, América Latina alcanzó elementos limitados, pero impresionante en el desarrollo tecnológico durante el período de la ISI. Con las garras del neoliberalismo ya debilitadas debido a los niveles de pésimo desempeño económico alcanzados en las últimas tres décadas, es demasiado pronto para descartar un período relativamente rápido de la prometedora evolución institucional, endógeno en algunas naciones que se incluyen en la promoción de las capacidades tecnológicas.

\section{CONCLUSIONES}

El desarrollo surge del apoyo de las fuerzas no-materiales, sobre todo de los conocimientos autóctonos y en especial de las capacidades tecnológicas. Celso Furtado, uno de los máximos exponentes del enfoque estructuralista latinoamericano, hizo hincapié en que cualquier análisis de las capacidades tecnológicas de América Latina tenía que ser contextualizado dentro de los parámetros estructurales históricamente determinados que definen el subdesarrollo. Al mismo tiempo, Furtado insistió en que estas condiciones eran superables. El análisis de Furtado y otros estructuralistas combinan bien con la visión del papel de la tecnología, como fue presentado por los que siguen un análisis tradicional enraizado en la economía política institucional, así como aquellos que operan con premisas y métodos desarrollados por los evolucionistas. 
Sin embargo, el marco estructuralista latinoamericano insiste en el énfasis de la tecnología combinando con el poder adquisitivo con un mejoramiento en la distribución del ingreso. En una expresión concreta de esta síntesis, Furtado destacó los vínculos (o su ausencia) entre las políticas industriales tecnológicamente centradas dando forma y fuerza para proyectos nacionales de desarrollo y la ampliación del mercado interno (Da Motta \& Albuquerque, 2007). En contraste, la adaptación tecnológica en América Latina ha sido principalmente un proceso que ha tomado de los estrechos límites del mercado interno como algo dado. Esto significa que las empresas privadas del sector en gran medida van a renunciar a los intentos de invertir en tecnologías de vanguardia por razones que sobrepasan explicaciones neoclásicas como "incertidumbre" y "riesgo" en la estimación de la rentabilidad de su inversión. (Aunque en años recientes, como hemos notado en la tercera sección - "el caso de Brasil" - los intentos de construir un SNI viable corresponden con las políticas económicas de mejoramientos en los salarios y en un programa masiva de reducir la tasa de pobreza.) Una estrategia 'furtadiana' sería la de ampliar el tamaño del mercado interno por medio de una reducción en la concentración del ingreso nacional $\mathrm{y}$, en el mismo momento, ocasionado un ensanchamiento en las capacidades de las fuerzas productivas de la industria de transformación a través de una política tecnológica viable, así generando complementariedades entre la demanda y la oferta agregada -como la realización de economías de escala- llevando a la sociedad a círculos virtuosos de crecimiento con efectos dinámicos de derrame y aprendizaje.

Basados en una lectura contemporánea de las obras claves de Furtado, Da Motta y Alburquerque sustentaron que América Latina no puede lograr avances sustantivos en la construcción de los SNI, sin políticas impulsadas por el Estado que trasciendan los límites de la era ISI, sobre todo en términos de la incapacidad estructural para formar las relaciones integradas entre el sector público y privado sobre la base de la autonomía limitada del Estado. Este tema, como hemos visto en la tercera sección, es una piedra angular del modelo exitoso de Asia, según autores como Shin, Wade y Wong (1996; 2010; 2004). Pero, como fue el caso de los países de Asia, es necesario que los países de América Latina lleven a cabo un proyecto nacional para reconstruir y ampliar en gran medida los limitados "estados de bienestar" de la era de la ISI. Sin una estrategia (o un enfoque relacionado que haga hincapié en la desigualdad en la distribución del ingreso, como ocurrió en Asia), América Latina se mantendrá anclada en una condición estructural a la que hace referencia Furtado, como la "industrialización dependiente". Esta condición, para Furtado, fue principalmente el resultado de la estructura social interna, no fue una creación de las empresas transnacionales, el capital financiero, las 
instituciones financieras internacionales o las políticas de los gobiernos de las naciones avanzadas.

En lugar de la construcción de un subsistema económico intensivo en el uso del capital/tecnología exógeno adaptado -que sólo se puede implementar de una manera muy limitada, dada la estrechez del mercado interno- Furtado buscó una estrategia que permitiera ampliar el mercado y al mismo tiempo fomentara el aprendizaje autónomo y, al final, la capacidad de crear tecnológica. Al avanzar en esta dirección, Furtado encontró que la principal barrera no era una de las capacidades, sino más bien una relación de poder socio-económico en el que los estratos dominantes carecían de la voluntad para reestructurar un sendero que permitiera un desarrollo tecnológico autónomo. En un análisis más reciente de la inercia estructural en América Latina, Cimoli y Rovira llegaron a una conclusión paralela (Cimoli \& Rovira, 2008). Furtado, sin embargo, no creyó que la solución para la dependencia tecnológica era la independencia tecnológica, sino la interdependencia. Es decir, cuando sostuvo que la estructura del subdesarrollo era superable, también entendía que dicho proceso era uno en donde Brasil se podría reinsertarse en base al nuevo poder de negociación en el sistema económico internacional. Para lograr esto, Furtado insistió en que sería necesario montar "un gigantesco esfuerzo para asimilar" el "know-how" tecnológico en una situación de profundo "desequilibrio en la asimilación de las nuevas tecnologías" (Furtado, 1968, p. $84-5 ; 1992$, p. 41). Cabe señalar que Furtado fue uno de los pocos que trabajaban dentro del estructuralismo latinoamericano que con tanta audacia hizo hincapié en la importancia del logro/ asimilación de las capacidades tecnológicas. Sin ese paso "gigantesco", la tecnología en uso no corresponde con las necesidades de la sociedad en general -lo cual sería "inapropiado" porque estaría meramente al servicio de un pequeño segmento de la sociedad, quienes extraen y consumen la mayor parte del excedente económico-. Por lo tanto cualquier dualismo o "heterogeneidad" es el resultado de una sociedad cada vez más desarticulada, sin un proyecto nacional de acumulación anclado en un estado de desarrollo.

En cuanto al tema del desarrollo endógeno de la ciencia y tecnología, como hemos anotado en la tercera sección, los esfuerzos de Brasil para promover las capacidades tecnológicas endógenas sugieren que este país ha hecho modestos, pero prometedores avances en los años recientes. El Estado brasileño busca recuperar su rol promotor/coordinador, haciendo hincapié en asociaciones públicoprivadas. Este paso se centrará en la mejora de una red nacional de proveedores de pequeñas y medianas empresas, la introducción de nuevas formas de apoyo, seguimiento y consulta. Las estrategias de desregulación y de liberación de mercados, predominantes en la década del noventa, están siendo desplazadas por una 
Instituciones y tecnología como factores clave en los proyectos nacionales del desarrollo J ames M artín Cypher - A ldo A lejandro Pérez-Estcatel

estrategia de "desarrollo a través de la innovación" y "crecimiento con redistribución”.

Mientras tanto, en el caso de México, hay un rechazo completo de la historia exitosa de la época de ISI -a pesar de los magros resultados de la política neoliberal desde 1981 (como hemos documentado en las Tablas 1 y 2 de la tercera sección)-. Para México, la falta de asignación de recursos hacia la CyT y la falta de la calidad de los recursos asignados, han sido un lastre estructural desde la época de ISI. Es decir que nunca han sido establecidas las relaciones complementarias y simbióticas necesarias entre las empresas, las universidades, las agencias del gobierno y los centros públicos de investigación para "proporcionar el aprendizaje interactivo" y generar las externalidades (que son los elementos claves e intrínsecos de un SNI). Apostando en los retornos fáciles rentistas basados en una apertura completa hacia el capital extranjero, México está a la deriva. Este país está sin políticas adecuadas para disciplinar o canalizar estas inversiones exógenas y promover efectos de externalidades y derrames hacía la base industrial nacional. Como hemos mencionado en la primera sección, las instituciones incrustadas pueden limitar el progreso económico ya que los "intereses creados" se esforzarán para bloquear los "huracanes de destrucción creativa". Sin un proyecto nacional de acumulación, con un rompimiento completo con su legacía instrumentalista de ISI, México es un caso paradigmático de la dominancia del ceremonialismo.

Sin embargo, hoy en día la gran espera de América Latina es que los cambios estructurales posneoliberales en Brasil, combinados con las transferencias de las lecciones desarrollistas de Asia (en cuanto a la política industrial y la política tecnológica), puedan servir para modelos en la promoción de un desarrollo endógeno integral, construido sobre la legacía de acumulación implantada en la época de ISI.

\section{R eferencias}

Amann, E. (2009.) Technology, Public Policy and the Emergence of Brazilian Multinationals. In L. Brainard \& L.Martínez-Díaz (Eds.). Brazil as an Economic Superpower?:Understanding Brazil's Changing Role in the Global Economy. (pp.187-220). Washington, DC: Brookings Institution Press.
Arbix, G. (2009, March 30-31). Innovation Policy Knowledge Base in Brazil. Vision Era net Workshop, Helsinki, Finland.

Arbix, G. e A. de Negri. (2009). Ainovação no centro da agenda do desenvolvimento. Em F. Giambiagi e O.de Barros (organziadores), Brasil Pós Crise.(pp. 325-344). Rio de Janeiro: Elsevier. 
Astorga, P. A. R. Bergés \& Fitzgerald, V. (2003). The Standard of Living in Latin America During the Twentieth Century. QEH Working Paper Series QEHWPS103. Oxford: Latin American Centre, St Antony's College. Retrieved from http://www3.qeh.ox.ac.uk/pdf/ qehwp/qehwps103.pdf

Ayres, C. (1995). Economic Development: An Institutional Perspective. James Dietz (Ed.), Latin America's Economic Development (pp. 89-97). Boulder, CO: Lynne Reinner Publishers.

Bértola, L. \& Ocampo, J.A. (2012). The Economic Development of Latin America since Independence. Oxford: Oxford University Press.

Boltvinik, J. \& Hernández, E. (1981). Origen del a crisis industrial: Elagotamiento del modelo de sustitución de importaciones. En R. Cordera(comp.). Desarrollo y crisisde la economía mexicana (pp. 456533). México: Fondo de Cultura Económica.

Barón, D. (2012). Pensamiento económico en América Latina (1950-2010). Apuntes del CENES, 31 (54), 37-72.

Bruton, H. (1998). A Reconsideration of Import Substitution. Journal of Economic Literature, 36 (3), 903-936.

Bulmer-Thomas, V. (1994). The Economic History of Latin America since Independence. Cambridge: Cambridge University Press.

Capdevielle, M. (2003). Composición tecnológica de la industria manufactura mexicana. En J. Aboites \& G. Dutrénit (Eds.). Innovación, aprendizaje y creación de capacidades tecnológicas (pp. 451-470). México: M.A. Porrúa.

Carleial, L. \& Cruz, B. (2011). A Hora e a Vez do Desenvolvimento Regional Brasileiro: uma proposta de longo prazo. (nãopublicado), p.p.1-32.
Castaldi, C., Cimoli, M.,Correa, N. \& Dosi, G. (2009). Technological Learning, Policy Regimes and Growth. In M. Cimoli, G. Dosi\& J. Stiglitz (Eds). Industrial Policy and Development (pp. 39-78). Oxford: Oxford University Press.

Castro, A. (2009). The Impact of Public Policies in Brazil. In M. Cimoli, G. Dosi \& J.Stiglitz, (Eds.). Industrial Policy and Development (pp. 257-276). Oxford: Oxford University Press.

Chang, H. (2003 $)$. Trade and Industrial Policy Issues. In H. Chang (Ed.). Rethinking Development Economics (pp. 257-276). London: Anthem Press.

Chang, H. $\left(2003^{\text {b }}\right)$. The Market, the State and Institutions. In H. Chang (Ed.), Rethinking Development Economics (pp. 41-60). London: Anthem Press.

Chang, H. $\left(2003^{c}\right)$. The East Asian Development Experience. In H. Chang (Ed.). Rethinking Development Economics (pp. 107-124). London: Anthem Press.

Cimoli, M. (2000). Conclusions: An Appreciative Pattern of the Mexican Innovation System. In M. Cimoli (Ed.). Developing Innovation Systems: Mexico in a Global Context (pp. 278-292). New York: Continuum.

Cimoli, M. \& S.Rovira. (2008). Elites and Structural Inertia in Latin America. Journal of Economic Issues, 42 (2), 327348.

Crespi, G. \& Zuñiga, P. (2010). Innovation and Productivity: Evidence from Six Latin American Nations. World Development, 40 (2), 273-290.

Cypher, J. (1989). The Debt Crisis as Opportunity. Latin American Perspectives, 16 (1), 52-78.

Cypher, J. (2009). El auge actual de los commodities y el proceso de primarización en América Latina ¿Al retorno al 
Instituciones y tecnología como factores clave en los proyectos nacionales del desarrollo James M artín Cypher - A ldo A lejandro Pérez-Estcatel

Siglo XIX? Foro Internacional, 49 (1), $119-162$.

Cypher, J. (2012, abril-junio). Veblen y el origen de la hipótesis del Catching-up. Problemas del Desarrollo 43, 9-26.

Cypher, J. \& Delgado, R. (2012). México a la deriva. México, D.F.: M.A. Porrúa.

Cypher, J. \& Dietz, J. (2009). The Process of Economic Development ( $\left.3^{\text {rd }} \mathrm{ed}\right)$. London: Routledge.

Da Motta \& Albuquerque, E. (2007). Inadequacy of technology and innovation systems at the periphery. Cambridge Journal of Economics, (31), 669-690.

Dalhman, C. \& Frischtak, C. (1993). National Systems Supporting Technical Advance in Industry: The Brazilian Experience.In R. Nelson (Ed.). National Innovation Systems (pp. 414-450). New York: Oxford University Press.

De Maria, Campos, M., Domínguez, L. \&Brown, F. (2012). La industria manufacturera en su encrucijada: evolución en los últimos treinta años. En J. Calva (coordinador). Nueva Estrategia de Industrialización (pp. 279-308). México: Juan Pablos Editor.

Dutrénit, G., Capdeville, M., Carona, J. M., Puchet, M., Santiago,F. \&Vera-Cruz, A. (2010). El sistema nacional de innovación mexicano. México: Universidad AutónomaMetropolitana.

Dutrénit, G., Puchet, M. \&Teubal, M. (2011). Building bridges between coevolutionary approaches to science, technology and innovation and development economics: an interpretive model. Innovation and Development, 1 (1), 51-74.

French-Davis, R., Muñoz, O. \& Palma. (1991). Las economíaslatinoamericanas, 19501990. En T. Halperin, W. Glade, R. Thorp,
A. Bauer, M. Moreno, C. Lewis, V. Bulmer-Thomas, R. Ffrench-Davis, O. Muñoz \& G. Palma. Historia Económica de América Latina (pp. 333-402). Barcelona, España: Crítica.

Furtado, A. \& Carvalho, R. (2005). Patterns of Technological Intensity in Brazil. Innovation: Management and Practice. Retrieved from: http://www.thefree library.com/Innovation:+Management,+ Policy,+\&+Practice/2005/April/1-p51562 Furtado, C. (1968). Um projeto para o Brasil. Rio de Janeiro: Saga.

Furtado, C. (1992). Brasil: a construção interrompida. São Paulo: Paz e Terra.

Giestreia, L. (2010). Desenvolvimento após o Desenvolvimentiso: Origens, Resultados e Limitaçoes da Política Brasileriera de Inovaço Tecnológica (1999-2008). Tesis doutoral,Instituto de Economia da UNICAMP, Campinas, Brasil.

Hira, A. (2007). An East Asian Model for Latin American Success. Aldershot, England: Ashgate.

Hirschman, A. (1989). Courcell-Seneuil, Jean Gustave. In J. Eatwell, M. Milgate\& P. Newman (Eds). The New Palgrave: Economic Development (pp. 88-90). New York: Norton.

Hodgson, G. (1998). Dichotomizing the Dichotomy: Veblen vs. Ayres.In S. Fayasmanesh \& M. Tool (Eds.). Institutional Method and ValueV.1 (pp. 48-73). Cheltenham, U.K.: Edward Elgar.

Hodgson, G. (2001). How Economics Forgot History. London: Routledge.

Hodgson, G. (2006). What are Institutions? Journal of Economic Issues, 40 (1), 1-26.

Katz, J. \& Kosacoff, B. (2003). El aprendizaje tecnológico, el desarrollo institucional y la microeconomía de la sustitución de importaciones. En E. Cárdenas et al. 
(comp.). Industrialización y Estado en la América Latina (pp. 58-84). México: Fondo de Cultura Económica.

Lall, S. \& Teubal, M.(1998). Market Stimulating Technology Policies in Developing Countries. World Development, 28 (8), 1369-1998.

Leonard, I. (2003). Science, Technology, and Hispanic America. In H. J. Wiarda \& M. MacLeish Mott (Eds.), Politics and Social Change in Latin America $\left(4^{\text {th }}\right.$ Edition), (pp. 79-90). Westport, Conn.: Praeger.

López, A. (2004). Una puesta en perspectiva de la industrialización sustitutiva de importaciones: los orígenes estructural e histórico del rezago de la Argentina. En R. Boyer \& J. Neffa (coordinadores). La economía argentino y su crisis (1976-2001) (pp. 349-378). Buenos Aires, Argentina: Miño y Dávila.

López, A. (2006). Empresarios, instituciones y desarrollo económico: el caso argentino. Buenos Aires, Argentina: CEPAL.

Love, J.(2005).The Rise and Decline of Economic Structuralism in Latin America. Latin American Research Review, 40 (3), 100-125.

Lundvall, B-Å., J. Vang, K.J. Joseph \& Chaminade, C. (2009). Innovation system research and developing countries. In BÅ. Lundvall, K.J. Joseph, C. Chaminade \& J.Vang, (Eds.), Handbook of Innovation Systems and Developing Countries. (pp. 1-32). Cheltenham, U.K.: Edward Elgar.

Mahoney, J. (2003). Long-Run Development and the Legacy of Colonial Spanish America. American Journal of Sociology. 109 (1), 50-106.

Martínez, J. (2011). Centripetal forces in aerospace clusters in Mexico. Innovation and Development, 1 (2), 303-318.

McKelvey, M. (1994). Innovation, National System of.In Geoffrey Hodgson, et al. (Eds.). Institutional and Evolutionary Economics, (pp. 366-369). Aldershot, England: Edgar Elgar.

Medialdea, B. (2012). Límites estructurales al desarrollo económico: Brasil (1950-2005). Problemas del Desarrollo (43), 55-82.

Ministério da Ciência e Tecnología. (2011). Indicadores consolidados: 2.1.2 Dispêdio nacional em ciência $e$ tecnologia. Recuperado de http:// www.mct.gov.br/index.php/content/ view/29140.html

Moreno-Brid, J. \& J. Ros Bosch. (2010). Desarrollo y crecimiento en la economía mexicana. México, D.F.: Fondo de Cultura Económica.

Nelson, R. (2008). What Enables Rapid Economic Progress?Research Policy, 37 (1), 1-11.

Nelson, R. (2009). Technology, Institutions and Economic Development. In W. Dreschsler, R. Kattel \& E. Reinert (Eds.). Techno-Economic Paradigms (pp. 271285). London: Anthem.

Nelson, R. (2011). Economic development as an evolutionary process. Innovation and Development, 1 (1), 39-49.

Nieto, C. (2005). Los amos de la guerra. Barcelona, España: Random House Mondadori.

O.E.C.D. (1997). Nacional Innovation Systems. Paris: O.E.C.D.

Pérez-Escatel, A. \& Pérez, O. (2009). Competitividad y acumulación de capacidades tecnológicas en la industria manufacturera. Investigación Económica, 68 (268), 159-187.

Pérez-Escatel, A. (2012). Competitividad y acumulación de capacidades tecnológicas. Zacatecas, México: Universidad 
Autónoma de Zacatecas.

Pietrobelli, C. \& R. Rabellotti. (2009). The Global Dimension of Innovation Systems.In B-A. Lundvall, K. J. Joseph, C. Chaminade \& J. Vang (Eds.)., Handbook of Innovation Systems and Developing Countries (pp. 214-240). Cheltenham, U.K.: Edward Elgar.

Rocha, A. y R. Lopez. (2003). Política en ciencia y tecnología en México. En J. Aboites \& G. Dutrénit (Eds.). Innovación, aprendizaje y creación de capacidades tecnológicas (pp. 103-134). México: M.A. Porrúa.

Romano, R. \& M. Carmangnani. (1999). Componentes Económicas. En M. Carmangnani, A. Hernández \& R. Romano (coordinadores). Para una historia de América I: las estructuras (pp. 160-287). México, D.F.: Fondo de Cultura Económica.

Shin, J-S. (1996). The Economics of the Latecomers. London: Routledge.

Sikkink, K. (1991). Ideas and Institutions: Developmentalism in Brazil and Argentina. Ithaca, New York: Cornell University Press.

Stein, S. \& B. Stein. (1970). The Colonial Heritage of LatinAmerica. New York: Oxford University Press.

Street, J. (1981). The Platt-Stein Controversy over Dependency: Another View.Latin American Research Review, 16 (3), 173180.

Sunkel, O. (1989). Structuralism, Dependency and Institutionalism.Journal of Economic Issues, 23 (2), 519-533.

Sunkel, O. (1990). Reflections on Latin
American Development. In J. Dietz \& D. James (Eds.). Progress Toward Development in Latin America (pp. 133158). Boulder, CO: Lynne Reinner Publishers.

Szmrecsányi, T. (2005). The contributions of Celso Furtado (1920-2004) to development economics.European Journal of the History of Economic Thought 12 (4), 689-700.

Thorp, R. (1991). Las economías latinoamericanas, 1939-1950. En T. Halperin, W. Glade, R. Thorp, A. Bauer, M. Moreno, C. Lewis, V. Bulmer-Thomas, R. Ffrench-Davis, Ó. Muñoz \& G. Palma. Historia Económica de América Latina (pp. 287-332). Barcelona, España: Crítica.

Thorp, R. (1998). Progress, Poverty and Exclusion. Washington: Interamerican Development Bank.

Wade, R. (2010). After the Crisis: Industrial Policy and the Developmental State in Low-Income Countries. Global Policy, $1(2), 150-161$.

Wong, J. (2004). The Adaptive Developmental State in East Asia. Journal of East Asian Studies, 4, 345362.

Worcester, D. (2003). The Spanish American Past: Enemy of Change. In H. J. Wiarda\& M. MacLeish Mott (Eds.), Politics and Social Change in Latin America $\left(4^{\text {th }}\right.$ Edition), (pp. 69-77). Westport, Conn.: Praeger. 